\title{
Plant developmental biology in the post-genomic era
}

\author{
Neelima Roy Sinha* \\ Department of Plant Biology, University of California Davis, Davis, CA, USA \\ *Correspondence: nrsinha@ucdavis.edu
}

At around the same time in the late 1960s, two great minds grappled with two seemingly different questions. Lewis Wolpert tackled the problem of how specific identities can be assigned to seemingly identical cells to generate a pattern. Theodosius Dobzhansky wondered why the living world was NOT a mass of one kind of living things, surviving in one special environment. Wolpert went on to use Turing's ideas of how pattern can be generated in a uniform field to provide positional information, which is then utilized to generate molecular readouts (Wolpert, 1969). Dobzhansky, in turn, described how combinations of genes could form a large but finite number of adaptive peaks, and each species then occupied a particular adaptive peak with reference to the gene combinations it utilized. The generation of heterogeneity in a sea of sameness was achieved at the levels of cells over time in development and at the level of individuals in a species during the course of evolution (Dobzhansky, 1970). A few years later, the two fields underwent a friendly collision, most notably with the publication of Gould's Ontogeny and Phylogeny, the attempt to relate embryonic development to evolution (Gould, 1977).

Developmental Biology itself progressed from classic descriptive and experimental studies on the generation of form, to the study of genes, and underlying genetic mechanisms. Once genes were identified one could look at the commonality or differences in developmental mechanisms across various phylogenetic levels. The use of reporter genes and in situ expression analyses filled in the details on where a gene product was present and the study of genetic mutations allowed elucidation of gene function. The gene-by-gene approach proved very fruitful and, combined with genetic analyses, allowed for the elucidation of developmental pathways in several model species. The focus on Arabidopsis thaliana as the premier model system, with the first completely sequenced genome, pushed the frontiers of plant developmental biology in the last decade.
However, the advent of genomics promised to change all fields of biological inquiry and make any organism accessible for study. There is no doubt having a sequenced genome makes an organism instantly amenable to many kinds of analyses. Chromosome walking, an exercise that consumed the entire career of a graduate student in the past, is now more like chromosome gazing for gene identification. One has instant access to promoters, gene structure, and, in some organisms, access to genome variation across accessions or cultivars. The ILLUMINA sequencing platform can now provide transcriptome profile data on a genome scale. When used between accessions, transcriptome profiling can, in addition to registering subtle changes in gene expression levels, provide information on variation at the level of sequence. Other emerging technologies have been coupled with genomics to generate very precise expression catalogs for tissues and cell types. These technologies include sorting of marked cells or tissues (Birnbaum et al., 2003), or laser capture microdissection (LCM) of cells or tissues (Kerk et al., 2003), followed by transcriptome profiling.

The challenges after such profiles are generated depend on how tractable the organism is for laboratory research and the questions that it is uniquely suited to answering. Research approaches can vary vastly between the well-developed models and non-models when it comes to understanding developmental mechanisms based on expression profiling. Comparison of global expression profiles of various floral organs across the Angiosperm phylogeny provided insights into the origin and subsequent diversification of flowers (Chanderbali et al., 2010). While functional validation of hypotheses poses a challenge in non-model systems, in the well-developed models the power of reverse genetics can prove very fruitful. Recent development of virus induced gene silencing (VIGS) in dicot (Dinesh-Kumar et al., 2003) and monocot plants (Holzberg et al., 2002; Scofield and Nelson, 2009) has brought reverse genetics, though in a transient and not stable mode, to many nonmodel species (Di Stilio et al., 2010; Preston and Hileman, 2010).

The clout provided by affordable and accessible high-throughput sequencing (along with limited reverse genetics tools) now opens up many classic questions to fresh ways of inquiry. However, while the selection of organisms to be sequenced has certain drivers - phylogenetic placement, unique morphologies, curious ecological niches, economic importance - none of these aims match with what makes an organism a suitable developmental model. At the very least factors like ease of cultivation under laboratory conditions, and the ability to take the organism through its complete life cycle within a reasonable time span, have to be considered when developing new model organisms.

Some issues we need to consider when it comes to future efforts to improve our knowledge of plant growth and development include:

1 Careful choice of organisms for genome initiatives. Considerations should include, in addition to the obvious factors like genome size and ploidy level, the viability as a genetic model system, and ease of experimental manipulation.

2 Transgenic technology needs to be streamlined and developed for all major plant clades. VIGS is an alternative but not well-developed for all clades, shows incomplete silencing, and study of genetic interactions is virtually impossible on the VIGS platform.

3 The most important need of the hour is high-throughput phenotyping to match the high-throughput genotyping efforts going on.

4 Above all, we have a crisis in training a lack of researchers who are trained to analyze and present data quantitatively, be it sequences, or high-throughput phenotyping, or modeling of developmental data. 
Of particular importance, in the world of changing ecological and climatological niches, will be our ability to identify organisms that inform on how plants can grow, develop, and adapt to changing conditions. The facility with which we can modify certain plants to meet our needs of food, feed, and fuel is tied into our understanding of how these organisms respond to their environments as they grow and develop. While growth measurements at the crude level can be automated, microscopic measurements are still a challenge, and a critical part of developmental biology - the ability to view development in time has only been achieved in very few systems (Reddy et al., 2004, 2007). The ability to model plant growth based on empirical data is growing by leaps and bounds (Jönsson and Krupinski, 2010; Prusinkiewicz and Barbier De Reuille, 2010), the next challenge is to utilize these models to predict genetic or developmental outcomes when key parameters are altered or key factors are missing, and then to test these models in systems that are genetically perturbed.

Plant Developmental Biology is on the threshold of wonderful discoveries as we begin to capitalize on genomics, evolutionary biology, and the efforts to decipher the relationships between all living things in the Tree of Life. The future looks promising as new quantitative and computer aided modeling tools, and precision dissection of gene expression, are being combined with highthroughput sequencing to answer age old questions of signaling and cell fate commitment during development of an organism.

\section{REFERENCES}

Birnbaum, K., Shasha, D. E., Wang, J. Y., Jung, J. W. Lambert, G. M., Galbraith, D. W., and Benfey, P. N. (2003). A gene expression map of the Arabidopsis root. Science 302, 1956-1960.

Chanderbali, A. S., Yoo, M. J., Zahn, L. M., Brockington, S. F., Wall, P. K., Gitzendanner, M. A., Albert, V. A., Leebens-Mack, J., Altman, N. S., Ma, H., Depamphilis, C. W., Soltis, D. E., and Soltis, P. S. (2010). Conservation and canalization of gene expression during angiosperm diversification accompany the origin and evolution of the flower. Proc. Natl. Acad. Sci. U.S.A. 107, 22570-22575.

Di Stilio, V. S., Kumar, R. A., Oddone, A. M., Tolkin, T. R., Salles, P., and Mccarty, K. (2010). Virus-induced gene silencing as a tool for comparative functional studies in Thalictrum. PLoS ONE 5, e12064. doi: 10.1371/ journal.pone.0012064

Dinesh-Kumar, S. P., Anandalakshmi, R., Marathe, R., Schiff, M., and Liu, Y. (2003). Virus-induced gene silencing. Methods Mol. Biol. 236, 287-294.

Dobzhansky, T. (1970). Genetics of the Evolutionary Process. New York: Columbia University Press.

Gould, S. J. (1977). Ontogeny and Phylogeny. Cambridge, MA: Belknap Press of Harvard University Press.

Holzberg, S., Brosio, P., Gross, C., and Pogue, G. P. (2002). Barley stripe mosaic virus-induced gene silencing in a monocot plant. Plant J. 30, 315-327.

Jönsson, H., and Krupinski, P. (2010). Modeling plant growth and pattern formation. Curr. Opin. Plant Biol. 13, 5-11.
Kerk, N. M., Ceserani, T., Tausta, S. L., Sussex, I. M., and Nelson, T. M. (2003). Laser capture microdissection of cells from plant tissues. Plant Physiol. 132, 27-35.

Preston, J. C., and Hileman, L. C. (2010). Squamosapromoter binding protein 1 initiates flowering in Antirrhinum majus through the activation of meristem identity genes. Plant J. 62, 704-712.

Prusinkiewicz, P., and Barbier De Reuille, P. (2010). Constraints of space in plant development. J. Exp. Bot. 61, 2117-2129.

Reddy, G. V., Gordon, S.P., and Meyerowitz, E. M. (2007). Unravelling developmental dynamics: transient intervention and live imaging in plants. Nat. Rev. Mol. Cell Biol. 8, 491-501.

Reddy, G. V., Heisler, M. G., Ehrhardt, D. W., and Meyerowitz, E. M. (2004). Real-time lineage analysis reveals oriented cell divisions associated with morphogenesis at the shoot apex of Arabidopsis thaliana. Development 131, 4225-4237.

Scofield, S. R., and Nelson, R. S. (2009). Resources for virus-induced gene silencing in the grasses. Plant Physiol. 149, 152-157.

Wolpert, L. (1969). Positional information and the spatial pattern of cellular differentiation. J. Theor. Biol. 25, 1-47.

Received:24March 2011; accepted: 14April 2011;published online: 27 April 2011.

Citation: Sinha NR (2011) Plant developmental biology in the post-genomic era. Front. Plant Sci. 2:11. doi: 10.3389/ fpls.2011.00011

This article was submitted to Frontiers in Plant Development, a specialty of Frontiers in Plant Science.

Copyright (c) 2011 Sinha. This is an open-access article subject to a non-exclusive license between the authors and Frontiers Media SA, which permits use, distribution and reproduction in other forums, provided the original authors and source are credited and other Frontiers conditions are complied with. 